\title{
Erratum to: Underrepresentation of Women Writers in Best American Anthologies: The Role of Writing Genre and Editor Gender
}

\author{
Jean Oggins
}

Published online: 9 September 2014

(C) Springer Science+Business Media New York 2014

\section{Erratum to: Sex Roles}

DOI 10.1007/s11199-014-0382-8

In Table 3, in the multiple regression, editor's female gender should be correlated with publication of women's writing in anthologies at $p=.07$ instead of at $p=.00$. Please find below corrected table.

Springer regrets the error.

Table 3 Predictors of likelihood of selection of women writers: Results from multiple logistic regression analysis

\begin{tabular}{|c|c|c|c|c|c|c|c|c|c|}
\hline \multirow{2}{*}{$\begin{array}{l}\text { Table } 3 \text { Predictors of likelihood } \\
\text { of selection of women writers: } \\
\text { Results from multiple logistic re- } \\
\text { gression analysis }\end{array}$} & & \multirow[b]{2}{*}{$B$} & \multirow[b]{2}{*}{$S E$} & \multirow[b]{2}{*}{ Wald $X^{2}$} & \multirow[b]{2}{*}{$d f$} & \multirow[b]{2}{*}{$p$} & \multirow[b]{2}{*}{$\operatorname{Exp}(B)$} & \multicolumn{2}{|c|}{$95 \% \mathrm{CI}$} \\
\hline & & & & & & & & Lower & Upper \\
\hline & Genre (Short stories as referent) & & & 138.83 & 5 & & & & \\
\hline & Poetry & -.25 & .09 & 6.94 & 1 & .01 & .78 & .65 & .94 \\
\hline & Essays & -.57 & .14 & 17.88 & 1 & .00 & .56 & .43 & .74 \\
\hline & Science & -1.02 & .20 & 26.21 & 1 & .00 & .36 & .24 & .53 \\
\hline & Travel & -1.29 & .22 & 35.16 & 1 & .00 & .27 & .18 & .42 \\
\hline & Sports & -1.93 & .20 & 96.07 & 1 & .00 & .15 & .10 & .21 \\
\hline & Gender of editor & .14 & .07 & 3.38 & 1 & .07 & 1.15 & .99 & 1.33 \\
\hline & Top-six source (Short stories top- & as referer & & & & & & & \\
\hline & Poetry top-6 & -.19 & .11 & 2.64 & 1 & .11 & .83 & .67 & 1.04 \\
\hline & Essay top-6 & -.38 & .19 & 4.09 & 1 & .04 & .69 & .47 & .99 \\
\hline & Travel top-6 & -.14 & .30 & .23 & 1 & .63 & .87 & .48 & 1.55 \\
\hline & Science top-6 - & -.63 & .29 & 4.74 & 1 & .03 & .53 & .30 & .94 \\
\hline & Sports top- 6 & -.18 & .29 & .38 & 1 & .54 & .84 & .48 & 1.47 \\
\hline & Year (Up to 2010 as referent) & & & & & & & & \\
\hline & 2011 & .43 & .16 & 7.03 & 1 & .01 & 1.53 & 1.12 & 2.10 \\
\hline & 2012 & .25 & .17 & 2.22 & 1 & .14 & 1.29 & .92 & 1.79 \\
\hline & Constant & -.22 & .08 & 6.71 & 1 & .01 & .81 & & \\
\hline
\end{tabular}

The online version of the original article can be found at http://dx.doi.org/ 10.1007/s11199-014-0382-8.

J. Oggins $(\bowtie)$

Consulting and Research/Evaluation Services, PO Box 426856,

San Francisco, CA 94142, USA

e-mail: jeanoggins@yahoo.com 